See Article page e353.

\section{Commentary: The Goldilocks annuloplasty: Not too big, not too small}

\author{
Kenza Rahmouni, MDCM, and \\ Fraser D. Rubens, MD, MSc, FACS, FRCSC
}

Surgical procedures are designed based on 2 major principles: there is a complete understanding of the mechanisms for the pathology, and the surgical strategy addresses these mechanisms to achieve normal physiology. In the case of functional tricuspid regurgitation (TR), the right-sided pressure and volume overload lead to right ventricular dilation, which in turn causes tricuspid annular dilation. This dilation is asymmetrical; the anterior and posterior leaflets are most affected, while the septal leaflet is relatively spared, supported by the ventricular septum. Therefore, surgical interventions for functional TR must be adapted to this pathophysiologic mechanism.

In this issue of the Journal, Malinowski and colleagues ${ }^{1}$ tested the validity of tricuspid annuloplasty for functional TR. To do so, they assessed the effect of various degrees of annular size reduction on leaflet motion and geometry of the tricuspid valve (TV) in an ovine model. They found that a $55 \%$ reduction in annular size was effective in diminishing TR, but that this degree of annular size reduction also induced nonphysiologic anterior and posterior leaflet motion. A more drastic annular reduction further impaired leaflet motion. These results are very plausible; there is nothing in the pathophysiologic mechanism of functional TR that insinuates that tricuspid annuloplasty should be performed with an aggressively undersized ring.

In fact, when surgeons apply this principle of tricuspid undersizing, it does not always work. In a recent

\footnotetext{
From the Division of Cardiac Surgery, University of Ottawa Heart Institute, Ottawa, Ontario, Canada.

Disclosures: The authors reported no conflicts of interest.

The Journal policy requires editors and reviewers to disclose conflicts of interest and to decline handling or reviewing manuscripts for which they may have a conflict of interest. The editors and reviewers of this article have no conflicts of interest.

Received for publication Feb 7, 2021; revisions received Feb 7, 2021; accepted for publication Feb 8, 2021; available ahead of print Feb 17, 2021

Address for reprints: Fraser D. Rubens, MD, MSc, FACS, FRCSC, Division of Cardiac Surgery, University of Ottawa Heart Institute, 40 Ruskin St, Ottawa, Ontario, Canada K1Y 4W7 (E-mail: FRubens@ottawaheart.ca).

J Thorac Cardiovasc Surg 2022;164:e367

$0022-5223 / \$ 36.00$

Copyright (c) 2021 by The American Association for Thoracic Surgery

https://doi.org/10.1016/j.jtcvs.2021.02.030
}

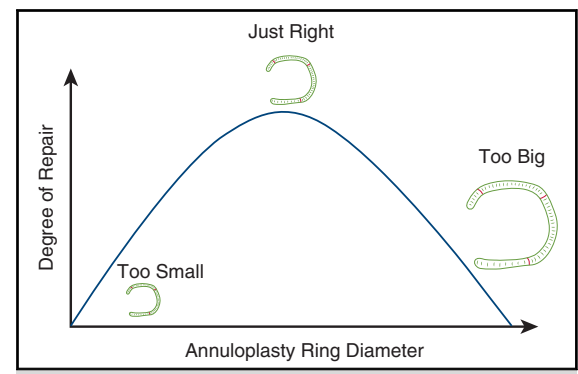

The tricuspid annuloplasty Goldilocks principle.

\section{CENTRAL MESSAGE}

Surgeons need to apply the

"Goldilocks principle" to

tricuspid valve repair by choosing

a ring that is just the right size to

observational

study, Brescia

and col-

leagues $^{2,3}$ re-

correct the regurgitation while

maintaining normal leaflet

motion.

ported an $11 \%$

rate of persis-

tent or recurrent TR at 3-year follow-up after TV repair and left-sided surgery, despite the use of small tricuspid annuloplasty rings ( 26 or $28 \mathrm{~mm}$ ). We can conclude from these results that TV undersizing is not the perfect and complete solution to functional TR, and that it does not always prevent TR recurrence. Malinowski and colleagues' experimental results lead us to think that the altered leaflet mobility caused by overly aggressive undersizing might explain why tricuspid annuloplasty sometimes fails to solve functional TR. Thus, surgeons need to apply the "Goldilocks principle" to TV repair; they need to choose a ring that is just the right size to correct the TR while maintaining normal leaflet motion. If the ring is too big, it does not solve the annular dilation, but if the ring is too small, it causes abnormal leaflet motion, which makes matters worse.

Because of the risk of TR recurrence after tricuspid annular undersizing, and notwithstanding the incremental risk of an added procedure, surgeons have been reticent to repair functional TR and do not attempt it as often as they should. ${ }^{2}$ We suspect suboptimal results from tricuspid annuloplasty, because aggressive undersizing addresses only part of the mechanism in functional TR. Therefore, we need to return to the fundamental surgical principles and correct the entire pathophysiology of the TR: annular measures with a goal of "Goldilocks normalcy." 


\section{References}

1. Malinowski M, Jazwiec T, Ferguson H, Bush J, Rausch MK, Timek TA. Tricuspid leaflet kinematics after annular size reduction in ovine functional tricuspid regurgitation. J Thorac Cardiovasc Surg. 2022;164:e353-66.
2. Brescia AA, Ward ST, Watt TMF, Romano MA, Bolling SF, on behalf of the Mich igan Mitral Research Group. Outcomes of guideline-directed concomitant annuloplasty for functional tricuspid regurgitation. Ann Thorac Surg. 2020;109:1227-32. 3. David TE. Invited commentary. Ann Thorac Surg. 2020;109:1232-3.
See Article page e353.

\section{Commentary: Primum non nocere}

\author{
Ankit Dhamija, MD, and Harold G. Roberts, Jr, MD
}

The surgical correction of functional tricuspid regurgitation (FTR) by reduction annuloplasty is an increasingly utilized procedure in the armamentarium of the cardiac surgeon. Malinowski and colleagues ${ }^{1}$ report an ovine model in which chronic epicardial pacing induced biventricular tachycardiamediated cardiomyopathy and moderate FTR. Ten sheep underwent placement of sonomicrometry crystals on the right ventricle epicardium, tricuspid annulus, leaflet body, and edges followed by a modified DeVega annuloplasty that was exteriorized to enable progressive cinching to produce tricuspid annular reduction (TAR). A total of 5 reductions (TAR 1-5) were carried out while evaluating biventricular function, tricuspid regurgitation (TR), tricuspid gradient, and various objective parameters by echocardiography. The main conclusion was that TAR of $55 \%$ perturbed anterior leaflet and posterior leaflet dynamics while maintaining normal septal leaflet motion. More profound TAR triggered severe changes in anterior leaflet and posterior leaflet excursion, closing angle, and strain, which suggested that aggressive undersizing impaired leaflet kinematics.

The ovine model is desirable over other nonprimate models due to its similarity to the human heart. ${ }^{2}$ The current study ${ }^{1}$ is elegant, and the authors are to be congratulated; however, there are limitations that should caution the direct application of its conclusions to clinical practice. The method of annuloplasty used was a modified DeVega suture annuloplasty. ${ }^{3,4}$ Remodeling annuloplasty applied for FTR

From the Department of Cardiovascular and Thoracic Surgery, West Virginia University, Morgantown, WVa.

Disclosures: The authors reported no conflicts of interest.

The Journal policy requires editors and reviewers to disclose conflicts of interest and to decline handling or reviewing manuscripts for which they may have a conflict of interest. The editors and reviewers of this article have no conflicts of interest.

Received for publication Feb 13, 2021; revisions received Feb 13, 2021; accepted for publication Feb 17, 2021; available ahead of print Feb 22, 2021.

Address for reprints: Harold G. Roberts, Jr, MD, Department of Cardiovascular and Thoracic Surgery, West Virginia University, 1 Medical Center Dr, Morgantown, WV 26505 (E-mail: harold.roberts@wvumedicine.org).

J Thorac Cardiovasc Surg 2022;164:e368-9

$0022-5223 / \$ 36.00$

Copyright (c) 2021 by The American Association for Thoracic Surgery

https://doi.org/10.1016/j.jtcvs.2021.02.063
Check for updates

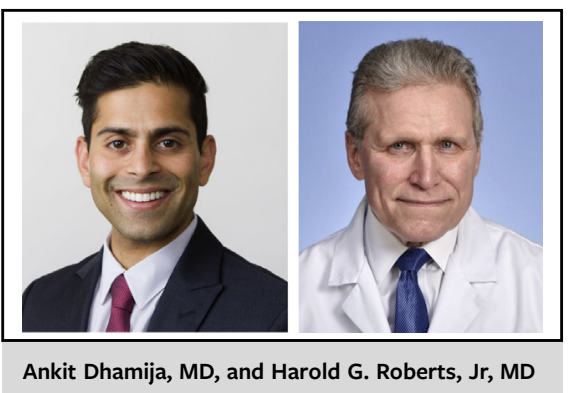

CENTRAL MESSAGE

Overzealous tricuspid annular

reduction severely impairs leaflet

mobility and could be inimical to

a satisfactory long-term result.

in the contemporary clinical setting utilizes rigid rings that often mimic the nonplanar geometry of the normal tricuspid annulus. ${ }^{5}$ It is quite conceivable or likely that leaflet mechanics by echo and sonomicrometry would be different with a rigid prosthesis to those produced by a simple, 2-dimensional, sutured annuloplasty. In addition, the influence of TAR on FTR was studied under acute conditions during the terminal procedure and did not allow animal recovery that might have produced different outcomes. Finally, sonomicrometry crystals by themselves may have influence on leaflet kinematics due to their weight and bending stiffness of associated wires. ${ }^{6}$

Nevertheless, the authors appear to effectively show that there may be a cost to leaflet excursion impairment from an undersized annuloplasty. Although progressive TAR abated TR, leaflet kinematics were impaired commensurate with degree of reduction. The average gradient for TAR-5 was only $3.6 \mathrm{~mm} \mathrm{Hg}$, a level that would not be expected to produce clinically relevant tricuspid stenosis. As the authors noted, leaflet tethering associated with restrictive mitral annuloplasty has been shown to induce biological changes in 